\title{
Antioxidant and Radical Scavenging Properties of 8-Oxo Derivatives of Xanthine Drugs Pentoxifylline and Lisofylline
}

\author{
Vadiraja B. Bhat* and K. M. Madyasthat, ${ }^{1}$ \\ †Department of Organic Chemistry, Indian Institute of Science, Bangalore 560 012, India; and \\ *Chemical Biology Unit, J NCASR, Bangalore 560 064, India
}

Received October 17, 2001

The antioxidant and radical scavenging properties of 8-oxo derivatives of pentoxifylline, lisofylline, enprofylline (3-propyl xanthine), and 1,7-dimethyl enprofylline were studied in vitro. The results show that 8-oxopentoxifylline and 8-oxolisofylline are significantly better hydroxyl and peroxyl radical scavengers and more potent inhibitors of t-butylhydroperoxideinduced lipid peroxidation in human erythrocyte membranes than the parent drugs. The hydroxyl radical scavenging property of 8-oxoenprofylline and its analogue 1,7-di methyl-8-oxoenprofylline is marginally better than their corresponding xanthines. Interestingly, 1,7-di methyl-8-oxoenprofylline is an effective inhibitor of lipid peroxidation whereas enprofylline, 1,7dimethylenprofylline, and 8-oxoenprofylline exhibit significantly less activity. All the 8-0xo derivatives tested are better hydroxyl radical scavengers than uric acid, a natural antioxidant and a free radical scavenger in humans. The rate constant for the reaction between 8-oxopentoxifylline and hydroxyl radical is 1.6-4.2 $\times 10^{10} \mathrm{M}^{-1} \mathrm{~s}^{-1}$ which is comparable to that of dimethyl sulfoxide $\left(1.4-1.6 \times 10^{10} \mathrm{M}^{-1} \mathrm{~s}^{-1}\right)$ and better than that of mannitol $\left(1.9-2.5 \times 10^{9} \mathrm{M}^{-1} \mathrm{~s}^{-1}\right)$, the known hydroxyl radical scavengers. Both 8-oxo pentoxifylline $\left({ }^{\prime} C_{50}, 1.8 \pm 0.08 \mu \mathrm{M}\right)$ and 8-oxolisofylline $\left(\right.$ IC $_{50}, 2.2 \pm 0.13$ $\mu \mathrm{M})$ are as efficient peroxyl radical scavengers as uric acid $\left(\mathrm{IC}_{50}, 1.9 \pm 0.05 \mu \mathrm{M}\right)$. The results presented clearly indicate that the anti-inflammatory property of pentoxifylline and lisofylline is exerted more through their 8-oxo derivatives than through the parent drugs. $\odot 2001$ Academic Press

Key Words: pentoxifylline; lisofylline; 8-oxo derivatives; antioxidant; hydroxyl and peroxyl radical scavenger; inhibitor of lipid peroxidation; anti-inflammatory.

\footnotetext{
${ }^{1}$ To whom correspondence and reprint requests should be addressed. Fax: 091-080-3600529. E-mail: kmm@orgchem.iisc.ernet.in.
}

Caffeine analogues such as pentoxifylline [I, 1-(5'oxohexyl)-3,7-dimethylxanthine] and lisofylline [II, 1-(5'-hydroxyhexyl)-3,7-dimethylxanthine] are used as drugs (1-3). Recent studies carried out using numerous purine analogues led to the selection of enprofylline (3-propylxanthine, III) as a drug with bronchodilator property (4). Pentoxifylline (I) is widely used in the treatment of cerebrovascular and peripheral vascular diseases (1-3). Both pentoxifylline (I) and lisofylline (II) are known to possess anti-inflammatory properties (5) which are probably related to their ability to suppress oxygen radical production or scavenge reactive oxygen species (6). Ability of I to scavenge hydroxyl radicals has been demonstrated earlier (7). Although substituted xanthines such as I and II are used as drugs, the corresponding 8-oxo derivatives have never been prepared and tested for their antioxidative potential and ability to scavenge reactive oxygen species. The nonavailability of the 8-oxo derivatives of these drugs has prevented their biological evaluation. It is quite possible that these drugs could become biotransformed to their corresponding 8-oxo derivatives in vivo which may be partly responsible for their biological activity. Caffeine, theophylline, and theobromine are known to become metabolized to their corresponding 8-oxo derivatives in the mammalian system $(8,9)$. These metabolites (methyluric acids) are known to inhibit lipid peroxidation in human erythrocyte membranes in vitro and function as free radical scavengers $(10,11)$ suggesting their antioxidant effects in vivo. In fact, Caffeine, theophylline and theobromine exhibit significantly less antioxidant and radical scavenging activity than the corresponding molecules without the 8-oxo group indicating that the 8-oxo-group of uric acid is an important functional moiety responsible for their high antioxidant and radical scavenging properties $(12,13)$.

In the present investigation, we have prepared for the first time 8-oxopentoxifylline [V, 1-(5'-oxohexyl)- 


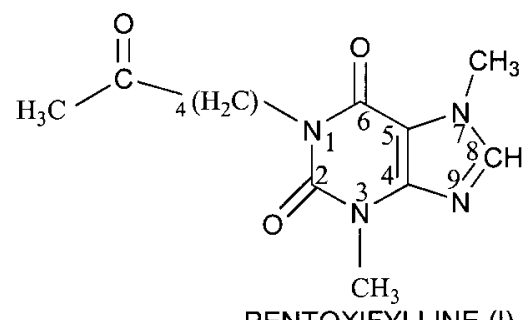

PENTOXIFYLLINE (l)<smiles></smiles>

LISOFYLLINE (II)<smiles>CCn1c(=O)[nH]c(=O)c2[nH]cnc21</smiles>

ENPROFYLLINE (III)<smiles>Cn1c(=O)c2c(ncn2C)n(C)c1=O</smiles>

$\left(\mathrm{CH}_{2}\right)_{2} \mathrm{CH}_{3}$

1,7 - DIMETHYL - 3 - PROPYLXANTHINE (IV)<smiles>O=c1[nH]c(=O)c2[nH]cnc2[nH]1</smiles>

XANTHINE<smiles></smiles>

8 - OXO PENTOXIFYLLINE (V)

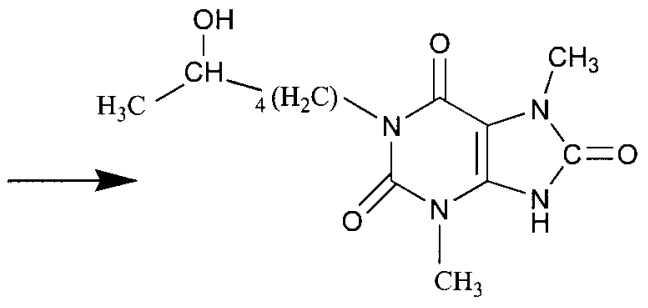

8 - OXO LISOFYLLINE (VI)<smiles>CCCCCn1c(=O)[nH]c(=O)c2[nH]c(=O)[nH]c21</smiles>

8 - OXO ENPROFYLLINE (VII)<smiles>CCCn1c(=O)n(C)c(=O)c2c1[nH]c(=O)n2C</smiles>

1,7 - DIMETHYL - 3 - PROPYLURIC ACID (VIII)<smiles>O=c1[nH]c(=O)c2[nH]c(=O)[nH]c2[nH]1</smiles>

URIC ACID

FIG. 1. Chemical structures of pentoxifylline, lisofylline, enprofylline, 1,7-dimethyl-3-propylxanthine, xanthine, and their corresponding 8-oxo derivatives.

3,7-dimethyluric acid], racemic 8-oxolisofylline [VI, 1-(5'-hydroxyhexyl)-3,7-dimethyluric acid] and 8-oxoenprofylline (VII , 3-propyluric acid) following a novel microbial method $(14,15)$. To increase the lipophilicity of enprofylline (III), we have substituted N-1 and N-7 hydrogens with methyl groups and the resulting compound viz. 1,7-dimethyl-3-propylxanthine (1,7-dimethylenprofylline, IV) was also microbially converted to 1,7-dimethyl-3-propyluric acid (VIII, 8-oxo deriva- tive of IV). All the 8-oxo compounds prepared (V-VIII, Fig. 1) were tested for their ability to scavenge hydroxyl and peroxyl radicals. These 8-oxo compounds were also tested for their protective potential against lipid peroxidation. These properties are compared with those observed from the corresponding xanthines (IIV, Fig. 1). The present study provides additional information to understand the mechanism of action of some of these drugs. 


\section{TABLE 1}

The Hydroxyl Radical Scavenging Ability of Pentoxifylline, Lisofylline, 1,7-Dimethylenprofylline, and Their Corresponding 8-Oxo Derivatives (Uric Acids)

Test compounds $(500 \mu \mathrm{M})$

Inhibition of deoxyribose degradation (\%)

$\begin{array}{ll}\text { Pentoxifylline (I) } & 31.0 \pm 1.3 \\ \text { Lisofylline (II) } & 42.0 \pm 1.0 \\ \text { Enprofylline (III) } & 50.7 \pm 2.3 \\ \text { 1,7-Dimethylenprofylline (IV) } & 43.1 \pm 3.8 \\ \text { 8-Oxopentoxifylline (V) } & 72.2 \pm 0.5 \\ \text { 8-Oxolisofylline (VI) } & 58.2 \pm 7.1 \\ \text { 8-Oxoenprofylline (VII) } & 53.6 \pm 0.7 \\ \text { 1,7-Dimethyl-8-oxoenprofylline (VIII) } & 52.1 \pm 1.3 \\ \text { Uric acid } & 50.1 \pm 0.1\end{array}$

a Deoxyribose degradation assay in the presence of various test compounds (500 $\mu \mathrm{M})$ was carried out as described under Materials and Methods. Results are expressed as percentage inhibition of deoxyribose degradation and values represent means \pm SD of triplicate experiments.

\section{MATERIALS AND METHODS:}

Chemicals. Uric acid, 2-thiobarbituric acid and 2-deoxyribose were obtained from Sigma, U.S.A. Enprofylline (3-propylxanthine) was a generous gift from Dr. Hans J urgen Fedrsel, Astra Production Chemicals AB, Sweden. Pentoxifylline was prepared using theobromine and alkyl halide as reported earlier (16). 3-Propyl-1,7-dimethylxanthine was prepared following the published procedure (17).

Preparation of 8-oxopentoxifylline, 8-oxoenprofylline and 3-propyl1,7-dimethyluric acid. A bacterial consortium consisting of strains belonging to the genera Klebsiella and Rhodococcus quantitatively converts pentoxifylline, enprofylline (3-propylxanthine) and 3-propyl-1,7-dimethylxanthine to their respective 8-oxo derivatives (Fig. 1 , substituted uric acids). The details of this microbial process have al ready been reported $(14,15)$. The 8-oxo derivatives prepared were characterized by comparing their spectral data to those reported earlier (15).

Preparation of 8-oxolisofylline [1-(5'-hydroxyhexyl)-3,7-dimethyluric acid]. Sodium borohydride reduction of 8-oxopentoxifylline yielded racemic 8-oxol isofylline. The compound was characterized by various spectral analyses [IR (nujol) $\gamma_{\max }\left(\mathrm{cm}^{-1}\right): 3300(-\mathrm{OH}), 1640,1680$ $(-\mathrm{NC}=\mathrm{O})$; ${ }^{1} \mathrm{HNMR}\left(300 \mathrm{MHz} \mathrm{CDCl}_{3}\right): \delta(\mathrm{ppm}) 1.45-1.73(6 \mathrm{H}, \mathrm{m}$, $\left.-\mathrm{CH}_{2}-\mathrm{CH}_{2}-\mathrm{CH}_{2}\right), 1.19\left(3 \mathrm{H}, \mathrm{d}, \mathrm{CH}_{3}-\mathrm{CHOH}-\right), 3.5\left(3 \mathrm{H}, \mathrm{s},-\mathrm{NCH}_{3}\right), 3.7$ $(1 \mathrm{H}, \mathrm{m},-\mathrm{CHOH}), 3.8\left(3 \mathrm{H}, \mathrm{s},-\mathrm{NCH}_{3}\right), 4.0\left(2 \mathrm{H}, \mathrm{t}, \mathrm{J}=7.2,-\mathrm{N}-\mathrm{CH}_{2}-\right) ;{ }^{13} \mathrm{C}$ NMR $\left(100 \mathrm{MHz} \mathrm{CDCl}_{3}\right)$ : $\delta 20.8,25.41,27.3,29.8,33.5,40.6,43.0$, $57.5,99.4,141.4,148,151,155$. Mass spectra: $\mathrm{m} / \mathrm{z} 296\left(\mathrm{M}^{+}\right), 196\left(\mathrm{M}^{+}\right.$ $-\mathrm{C}_{6} \mathrm{H}_{12} \mathrm{O}$, base peak), $153\left(\mathrm{M}^{+}-\mathrm{C}_{6} \mathrm{H}_{12} \mathrm{O}-\mathrm{CO}-\mathrm{CH}_{3}\right), 125\left(\mathrm{M}^{+}-\mathrm{C}_{6} \mathrm{H}_{12} \mathrm{O}\right.$ $\left.2 \mathrm{CO}-\mathrm{CH}_{3}\right), 97\left(\mathrm{M}^{+}-\mathrm{C}_{6} \mathrm{H}_{12} \mathrm{O}-2 \mathrm{CO}-\mathrm{CH}_{3}-\mathrm{N}_{2}\right), 82\left(\mathrm{M}^{+}-\mathrm{C}_{6} \mathrm{H}_{12} \mathrm{O}-2 \mathrm{CO}-\right.$ $\left.2 \mathrm{CH}_{3}-\mathrm{N}_{2}\right)$ ].

Measuring hydroxyl radical scavenging. Hydroxyl radicals were generated by a mixture of ascorbic acid, $\mathrm{H}_{2} \mathrm{O}_{2}$ and $\mathrm{Fe}^{2+}-$ EDTA and estimated using the 2-deoxyribose method (18). Each assay contained 2-deoxyribose (2.8 mM), ferrous iron solution (20 $\mu \mathrm{M})$, EDTA $(100 \mu \mathrm{M})$ and one of the test compounds $(500 \mu \mathrm{M})$ in a total volume of $1.2 \mathrm{ml}$ of phosphate buffer (10 mM, pH 7.4). The ferrous iron solution and EDTA were premixed before they were added to the assay mixture. The reaction was initiated by the addition of a mixture of $\mathrm{H}_{2} \mathrm{O}_{2}(1.42 \mathrm{mM})$ and ascorbate $(100 \mu \mathrm{M})$, and incubated at $37^{\circ} \mathrm{C}$ for $30 \mathrm{~min}$. Then $1 \mathrm{ml}$ of thiobarbituric acid $(1 \%, w / v)$ in $\mathrm{NaOH}$ $(50 \mathrm{mM})$ and $1 \mathrm{ml}$ of TCA $(2.8 \%, \mathrm{w} / \mathrm{v})$ were added, boiled for $20 \mathrm{~min}$, cooled and the absorbance was measured at $532 \mathrm{~nm}$. The results are expressed as percentage inhibition by test compounds. The assay was repeated at different concentrations (10-500 $\mu \mathrm{M})$ of test compounds (V-VIII, and uric acid). Reciprocal absorption values obtained for different concentrations were plotted against the concentrations of the test compounds and from the graph the second order rate constants for the reaction of test compounds with hydroxyl radical were calculated assuming that deoxyribose reacts with hydroxyl radical with a rate constant of $3.1 \times 10^{9} \mathrm{M}^{-1} \mathrm{~s}^{-1}$ (18). In a similar way the rate constants for established scavengers of hydroxyl radical such as mannitol and dimethyl sulfoxide were determined.

Measuring peroxyl radical scavenging. Peroxyl radical scavenging activity of test compounds was measured by competition kinetics of crocin bleaching in the presence of peroxyl radicals generated by thermal decomposition of a azo compound as reported earlier $(19,20)$.

Lipid peroxidation in human erythrocyte membranes. Effect of test compounds on t-butylhydroperoxide-induced lipid peroxidation in human erythrocyte membranes was assayed as reported earlier $(10,21)$. Washed erythrocyte membranes were prepared and processed as reported earlier (21). The peroxidation of lipids in erythrocyte membranes was carried out in $1.0 \mathrm{ml}$ total volume containing $2.0 \mathrm{mg}$ protein, with or without the test compounds. The reaction was started by the addition of t-butylhydroperoxide ( $1 \mathrm{mM})$ and incubated at $37^{\circ} \mathrm{C}$ for $15 \mathrm{~min}$. The extent of peroxidation was assayed by measuring thiobarbituric acid-reactive substances (TBARS) in membranes as described earlier (22). The results are expressed as percentage inhibition which represents the degree of protection by the test compounds against lipid peroxidation in erythrocyte membranes.

Protein was estimated by the method of Lowry et al. (23).

\section{RESULTS AND DISCUSSION}

Reactive oxygen species produced by activated polymorphonucl ear leukocytes appear to be responsible for tissue damage in a number of inflammatory conditions

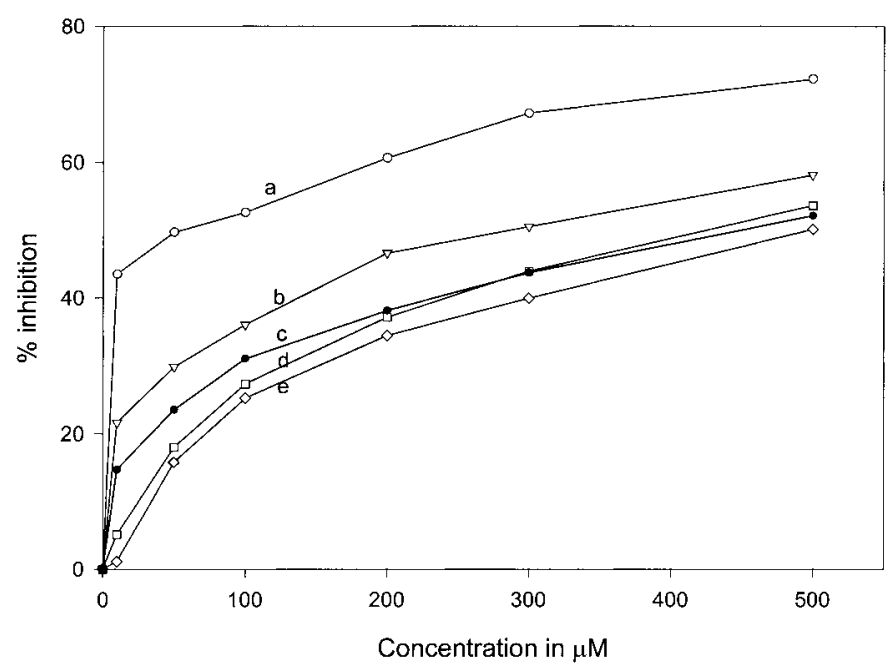

FIG. 2. Effect of various concentrations of test compounds (a) 8-oxopentoxifylline, (b) 8-oxolisofylline, (c) 1,7-dimethyl-8oxoenprofylline, (d) 8-oxoenprofylline, and (e) uric acid on deoxyribose degradation. Results are expressed as percentage inhibition of deoxyribose degradation. Experimental details are mentioned in the text. 
TABLE 2

Inhibitory Effect of Test Compounds on tert-Butylhydroperoxide (1 mM)-Induced Lipid Peroxidation in Human Erythrocyte Membranes

\begin{tabular}{lc}
\hline \multicolumn{1}{c}{ Test compounds (500 $\mu \mathrm{M})$} & Inhibition (\%) $^{\mathrm{a}}$ \\
\hline Pentoxifylline (I) & $10.5 \pm 0.5$ \\
Enprofylline (III) & $14.2 \pm 2.6$ \\
1,7-Dimethylenprofylline (IV) & $23.7 \pm 4.7$ \\
8-Oxopentoxifylline (V) & $41.4 \pm 2.4$ \\
8-Oxolisofylline (VI) & $51.3 \pm 0.8$ \\
8-Oxoenprofylline (VII) & $11.8 \pm 1.8$ \\
1,7-Dimethyl 8-oxoenprofylline (VIII) & $62.9 \pm 1.7$ \\
\hline
\end{tabular}

\footnotetext{
${ }^{a}$ Results are expressed as percentage inhibition of lipid peroxidation. Values represent means \pm SD of triplicate experiments. Details of the experiment are given in the text.
}

(24). Earlier studies have indicated that xanthine drug, pentoxifylline (I) reduces oxygen radical production and protects against tissue damage in vivo by the action of its metabolites (25). In fact, both pentoxifylline (I) and lisofylline (II) are known for their antiinflammatory properties $(5,6)$. It is also known that I inhibits hydroxyl radical-mediated degradation of deoxyribose (7).

In the present study we have prepared 8-oxopentoxifylline $(\mathrm{V})$, 8-oxolisofylline $(\mathrm{VI})$, 8-oxoenprofylline (VII) and 1,7-dimethyl-8-oxoenprofylline (VIII). All the 8-oxo compounds prepared are water soluble and stable in the aqueous medium. The present study demonstrates for the first time that $\mathrm{V}$ and $\mathrm{VI}$ are significantly better hydroxyl radical scavengers than the parent drugs (I and II, Table 1), whereas VII and VIII show marginally better activity than the corresponding xanthines (III and IV, Table I). It has been noticed that 8-oxopentoxifylline ( $\mathrm{V}$ ) is a much better scavenger of hydroxyl radicals than 8-oxolisofylline (VI) at all concentrations tested (Fig. 2). This could be possibly due to the fact that racemic 8-oxolisofylline (VI) was used in this study. It is known that R-isomer of lisofylline is biologically more active than its optical antipode (26). All the 8-oxo compounds tested (V-VIII) inhibit the degradation of deoxyribose in a dose dependent manner and compounds $\mathrm{V}$ and $\mathrm{VI}$ are very efficient at lower concentrations (10-50 $\mu \mathrm{M}$, Fig. 2). It is interesting to note that 8-oxo compounds (V-VIII) exhibit better activity than the physiological antioxidant, uric acid (21) at all the concentrations tested (Fig. 2). In fact, $500 \mu \mathrm{M}$ concentration of uric acid scavenged hydroxyl radicals to an extent comparable to $50 \mu \mathrm{M}$ concentration of 8-oxopentoxifylline (V, Fig. 2) indicating that $\mathrm{V}$ is a more potent scavenger of hydroxyl radicals than uric acid. It has been reported earlier that uric acid and related analogues function as efficient antioxidant and free radical scavengers $(12,21,27,28)$ and protect erythrocyte membranes from lipid peroxidation (10, 11, 28).
It was observed that 8-oxopentoxifylline (V) show high hydroxyl radical scavenging property (Ks, 1.6$4.2 \times 10^{10} \mathrm{M}^{-1} \mathrm{~s}^{-1}$ ) with an effectiveness comparable to that of dimethyl sulfoxide $\left(\mathrm{Ks}, 1.4-1.6 \times 10^{10} \mathrm{M}^{-} 1 \mathrm{~s}^{-1}\right)$ and better than mannitol $\left(\mathrm{Ks}, 1.9-2.5 \times 10^{9} \mathrm{M}^{-1} \mathrm{~s}^{-1}\right)$. The rate constants obtained for dimethyl sulfoxide and mannitol compared well with the reported values (18). The second order rate constant (Ks) reported earlier (7) for pentoxifylline (I) with hydroxyl radicals indicates that $\mathrm{V}$ is a more effective hydroxyl radical scavenger than is I. Similar observation was also made earlier with allopurinol and oxypurinol (29). Oxypurinol, a major metabolite of allopurinol is a better hydroxyl radical scavenger than is allopurinol (29).

Earlier studies have shown that 1,3-dimethyluric acid and 1,3,7-trimethyluric acid have high potency in prevention of hydrogen peroxide induced lipid peroxidation in human erythrocyte membranes in vitro (10). In fact, V and VI are analogues of 1,3,7trimethyluric acid where $\mathrm{N}-1$ position is substituted with 5-oxohexyl/5-hydroxyhexyl group. The present study has shown that compounds V, VI, and VIII significantly suppress t-butylhydroperoxide-induced lipid peroxidation in human erythrocyte membranes, whereas compounds I, III and VII show markedly less activity (Table 2). The antioxidative effect of compounds V, VI, and VIII is evidenced by their ability to scavenge hydroxyl radicals very efficiently (Table 1). The ability of uric acid to inhibit lipid peroxidation in erythrocyte membranes is known (10). However, it is interesting to note that when N-3 hydrogen in uric acid is substituted by a propyl group as in 3-propyluric acid (8-oxoenpropylline, VII), the compound very poorly protected erythrocyte

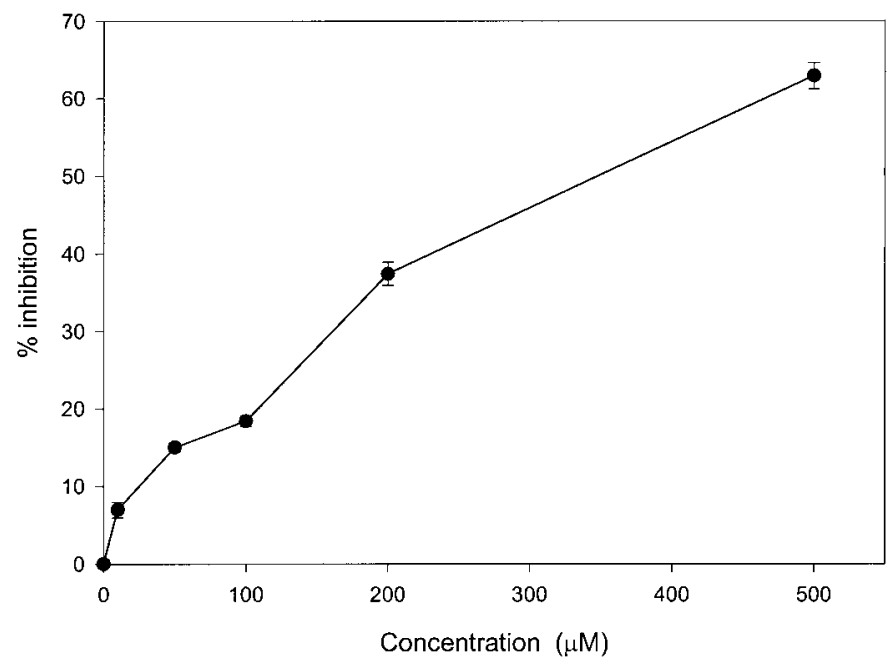

FIG. 3. Effect of different concentration of 1,7-dimethyl-8oxoenprofylline on t-butylhydroperoxide-induced lipid peroxidation in human erythrocyte membranes. Results are expressed as percentage inhibition of lipid peroxidation. Experimental details are mentioned in the text. 
membranes from lipid peroxidation (Table 2). Surprisingly, 3-propyl-1,7-dimethyluric acid (VIII) shows very good activity as the inhibitor of lipid peroxidation (Table 2). The inhibitory effects of different concentrations of VIII on lipid peroxidation by a fixed dose of t-butylhydroperoxide are shown to be dose dependent (Fig. 3). It is interesting to note that VII and VIII which differ in methyl substitution at N-1 and N-7 positions, exhibit significant difference in potency in preventing lipid peroxidation in erythrocyte membranes in vitro (Table 2). This appears to be contrary to what has been suggested earlier that a methyl group at the N-7 position in a xanthine molecule would adversely affect the antioxidant activity (30). It is quite possible that the structural variations could change the lipophilicity and inhibition of lipid peroxidation seems to be related to the lipophilicity of the compounds tested.

Earlier studies have demonstrated that uric acid has the ability to scavenge peroxyl radicals (31). Peroxyl radicals are highly reactive and can give rise to hydroperoxides and lead to lipid peroxidation (32). In the present study we have analyzed the peroxyl radical scavenging ability of 8-oxopentoxifylline (V) and 8-oxolisofylline (VI) by competition kinetics of crocin bleaching. It was observed that $\mathrm{V}$ and $\mathrm{VI}$ are good peroxyl radical scavengers with an $\mathrm{IC}_{50}$ values of $1.8 \pm$ 0.08 and $2.2 \pm 0.13 \mu \mathrm{M}$, respectively (Table 3 ). It appears that both $\mathrm{V}$ and $\mathrm{VI}$ are as efficient peroxyl radical scavengers as uric acid $\left(\mathrm{IC}_{50}, 1.9 \pm 0.05 \mu \mathrm{M}\right)$ at all concentrations tested (Fig. 4). However, pentoxifylline (I), lisofylline (II) and xanthine failed to scavenge peroxyl radical indicating the importance of 8-oxo group in urates for their antioxidant and radical scavenging properties.

Earlier studies have established that the 8-oxo group of urates is an important functional moiety responsible for high hydroxyl radical scavenging and antioxidant properties $(12,13)$. It is quite possible that pentoxifylline (I) and lisofylline (II) could become converted to their corresponding 8-oxo derivatives in vivo as one of their metabolites. This is supported by the fact that caffeine, theophylline and theobromine become metabolized in the mammalian system to their corresponding 8-oxo derivatives $(8,9)$ and these metabolites are

\section{TABLE 3}

$\mathrm{IC}_{50}$ Values for Uric Acid, 8-Oxopentoxifylline, and 8-Oxolisofylline for Inhibition of the Peroxyl Radical-Mediated Reaction

\begin{tabular}{ll}
\multicolumn{1}{c}{ Compounds } & $\mathrm{IC}_{50}(\mu \mathrm{M})$ \\
\hline Uric acid & $1.9 \pm 0.05$ \\
8-Oxopentoxifylline (V) & $1.8 \pm 0.08$ \\
8-Oxolisoifylline (VI) & $2.2 \pm 0.13$
\end{tabular}

\footnotetext{
${ }^{a}$ Values represent means \pm SD of triplicate experiments.
}

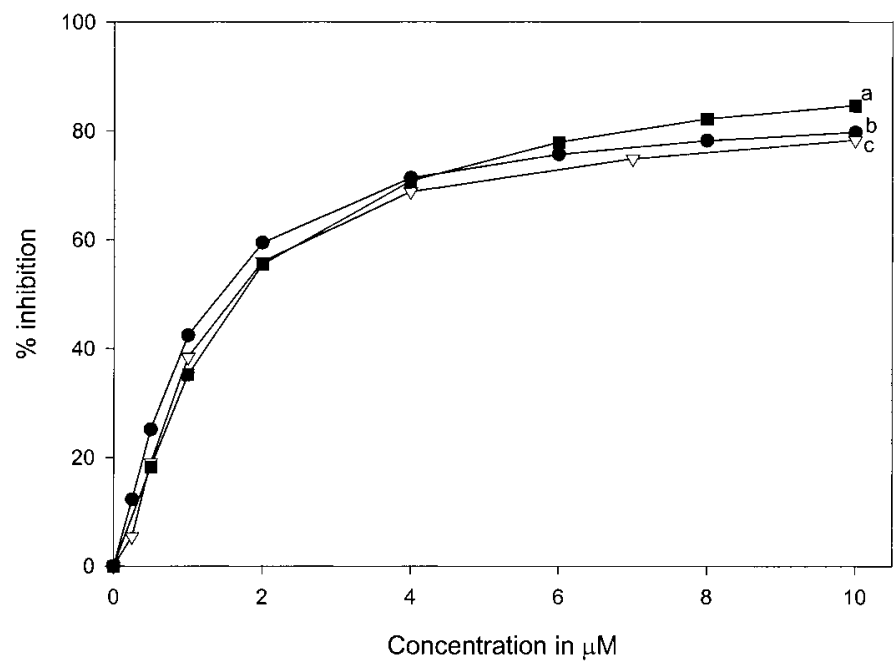

FIG. 4. Effect of different concentrations of test compounds (a) uric acid, (b) 8-oxopentoxifylline, and (c) 8-oxolisofylline on crocin bleaching by peroxyl radical. Results are expressed as percentage inhibition of crocin bleaching. Experimental details are mentioned in the text.

known to inhibit lipid peroxidation in human erythrocyte membranes in vitro $(10,11)$. The observation made in the present investigation that 8-oxopentoxifylline (V) and 8-oxolisofylline (VI) are much better hydroxyl and peroxyl radical scavengers and more potent inhibitors of lipid peroxidation than the parent drugs (I and II) suggests the possibility that the beneficial effects of pentoxifylline (I) and lisofylline (II), particularly their anti-inflammatory and antioxidant properties are exerted more through their 8-oxo derivatives rather than the parent compounds.

\section{ACKNOWLEDGMENTS}

Financial assistance from CSIR (New Delhi, India) and J NCASR (Bangalore, India) is gratefully acknowledged.

\section{REFERENCES}

1. Mansfield, H. G. (1972) Deutsch. Med. J . 23, 1-12.

2. Dench, H. (1973) Arzneim. Forsch. 23, 571-573.

3. Aviado, D. M., and Porter, J. M. (1984) Pharmacotherapy 6, 297-307.

4. Persson, C. G. A., and Kjellin, G. (1981) Acta Pharmacol. Toxicol. 49, 313.

5. Sullivan, G. W., Patsclas, T. N., Redick, J . A., and Mandell, G. L. (1984) Transact. Assoc. Am. Physicians 97, 337-345.

6. Pasquier, C., Franzini, E., Abedinzadeh, Z., Kaouadji, M. N., and Hakin, J. C. (1991) Int. J . Radiat. Biol. 60, 433- 447.

7. Freitas, J. P., and Filipe, P. M. (1995) Biol. Trace Elem. Res. 47, 307-311.

8. Khanna, K. L., Rao, G. S., and Cornish, H. H. (1972) Toxicol. Appl. Pharmacol. 23, 720-730.

9. Arnaud, M. J ., and Welsch, C. (1979) J . Agric. Food Chem. 27, 524-527.

10. Nishida, Y. (1991) J . Pharm. Pharmacol . 43, 885- 887. 
11. Schlotte, V., Sevanian, A., Hochstein, P., and Weithmann, K. U. (1998) Free Radical Biol. Med. 25, 839-847.

12. Simic, M. G., and J ovanovic, S. V. (1989) J . Am. Chem. Soc. 111, 5778-5782.

13. Maples, K. R., and Mason, R. P. (1988) J. Biol. Chem. 263, 1709-1712.

14. Madyastha, K. M., and Sridhar, G. R. (1998) Biochem. Biophys. Res. Commun. 248, 178-181.

15. Madyastha, K. M., and Sridhar, G. R. (1999) J. Chem. Soc. Perkin Trans. 1, 677- 680.

16. Wang, C-H., Wang, J -S., and Chen, C-T. (1981) Bull. Inst. Chem. Acad. Sin. 28, 69-70.

17. Daly, J . W., Padgett, W. L., and Shamim, M. T. (1982) J . Med. Chem. 29, 1305-1308.

18. Halliwell, B., Gutteridge, J. M. C., and Aruoma, O. I. (1987) Anal. Biochem. 165, 215-219.

19. Bors, W., Michel, C., and Saran, M. (1984) Biochim. Biophys. Act. 796, 312-319.

20. Bhat, V. B., and Madyastha, K. M. (2000) Biochem. Biophys. Res. Commun. 275, 20-25.

21. Ames, B. N., Cathcart, R., Schwiers, E., and Hochstein, P. (1981) Proc. Natl. Acad. Sci. USA 78, 6858-6862.
22. Buge, J. A., and Aust, S. D. (1979) Methods Enzymol. 52, 302310.

23. Lowry, O. H., Rosebrough, N. J ., Farr, A. L., and Randall, R. J . (1951) J . Biol. Chem. 193, 265-268.

24. Schmid-Schonbein, G. W., and Engler, R. L. (1986) Am. J . Cardiovasc. Pathol. 1, 15-30.

25. Crouch, S. P. M., and Fletcher, J . (1992) Infect. Immun. 60, 4504- 4509.

26. Lillibridge, J . A., Kalhorn, T. F., and Slattery, J . T. (1996) Drug Metab. Dispos. 24, 1174-1179.

27. Smith, R. C., and Lawing, L. (1983) Arch. Biochim. Biophys. 223, 166-172.

28. Bhat, V. B., Sridhar, G. R., and Madyastha, K. M. (2001) Life Sci., in press.

29. Moorhouse, P. C., Grootveld, M., Halliwell, B., Quinlan, J. G., and Gutteridge, J. M. C. (1987) FEBS Lett. 213, 23-28.

30. Lee, C. (2000) Clin. Chim. Acta 295, 141-154.

31. Lussignoli, S., Fraccaroli, M., Andrioli, G., Brocco, G., and Bellavite, P. (1999) Anal. Biochem. 269, 38- 44.

32. Halliwell, B., and Gutteridge, J . M. C. (1990) Methods Enzymol. 186, 1- 85 . 